\title{
Tinjauan Etika terhadap Praktik Polifarmasi dalam Layanan Kedokteran
}

\author{
Rianto Setiabudy ${ }^{\mathrm{I}, 2}$, Ali Sulaiman ${ }^{\mathrm{I}}$, Frans Santosa ${ }^{\mathrm{I}, 3}$, Julitasari Sundoro ${ }^{\mathrm{I}, 4}$, Fadlika Harinda \\ ${ }^{\mathrm{I}}$ Majelis Kehormatan Etik Kedokteran Pengurus Besar Ikatan Dokter Indonesia \\ ${ }^{2}$ Departemen Farmakologi, Fakultas Kedokteran Universitas Indonesia, Jakarta \\ ${ }^{3}$ Fakultas Kedokteran Universitas Pembangunan Nasional Veteran Jakarta \\ ${ }^{4}$ The Indonesian Technical Advisory Group on Immunization Communicable Disease Control (ITAGI CDC)
}

\author{
Kata Kunci \\ Etika, polifarmasi, peresepan rasional, \\ puyer \\ Korespondensi \\ contact@ilmiah.id \\ Publikasi \\ (C) $2020 \mathrm{JEKI} /$ ilmiah.id \\ DOI \\ I0.26880/jeki.v4ir.44 \\ Tanggal masuk: Io Desember 2019 \\ Tanggal ditelaah: I2 Januari 2020 \\ Tanggal diterima: Io Februari 2020 \\ Tanggal publikasi: 24 Februari 2020
}

\begin{abstract}
Abstrak Adanya pemikiran zaman dulu di mana kombinasi obat termasuk dalam seni kedokteran (art of medicine) kini sudah harus digeser ke arah pelayanan kedokteran berbasis bukti (evidencebased mediane) dan precision medicine Fenomena polifarmasi masih banyak dijumpai dalam layanan kesehatan di Indonesia maupun di dunia. Menurut tinjauan etik, polifarmasi merupakan praktik medis yang potensial merugikan pasien baik dari segi keselamatan (patient safey) maupun dari segi biaya pengobatan. Sebagai seorang dokter, peresepan rasional dengan mempertimbangkan risk benefit dan cost harus dilakukan. Dokter bertanggung jawab penuh sesuai kompetensinya dan harus memberikan penjelasan mengenai obat-obatan dan efek samping.
\end{abstract}

Abstract The traditional belief that polypharmacy is a form of the art of medicine must now be shifted towards evidence-based medicine and precision medicine. Until now, polypharmacy is still a common phenomenon locally as well as globally. From an ethical point of view, polypharmacy is a medical practice that could potentially harm patients, both in terms of patient safety and medical costs. As a doctor, rational prescribing by considering the risks, benefits, and costs must be performed. The doctor takes full responsibility according to his competence and must provide an explanation of the drugs and side effects.

Hingga saat ini, fenomena peresepan terlalu banyak obat di saat yang bersamaan (polifarmasi) masih banyak dijumpai dalam layanan kesehatan di berbagai belahan dunia. Prevalensi polifarmasi menurut laporan kepustakaan mencapai 38,1-91,2\%. ${ }^{1-2}$ Dari penelitian yang dilakukan di RSUD Saiful Anwar Malang, didapatkan hasil praktik polifarmasi terjadi pada $72 \%$ pasien geriatri. Adapun $70 \%$ dari praktik polifarmasi tersebut menimbulkan permasalahan terkait pemberian obat (Drug-Related Problem, DRP). Kejadian DRP tersering antara lain potensi interaksi obat (66\%), dosis yang tidak tepat $(17,3 \%)$, pemakaian obat yang tidak perlu (16\%), efek samping obat $(14 \%)$, dan pemilihan jenis obat yang tidak tepat $(8,7 \%){ }^{3}$

Meskipun pasien berhak memilih dengan siapa dia ingin berobat dan pilihan pengobatan apa yang ingin dilakukannya sebagai bentuk realisasi asas autonomi dalam etika kedokteran, pengetahuan yang minim tentang obat yang beredar, baik jenis, efek terapi, dan efek samping membuat masyarakat biasanya menyerahkan pilihan jenis obat yang diresepkan sepenuhnya kepada dokter. Di era sekarang, di mana pilihan obat sudah sangat beragam, seorang dokter harus memastikan bahwa obat-obatan yang diberikan pada pasiennya sesuai indikasi medis dan aman, tetapi tetap dengan harga yang terjangkau.

\section{Fenomena Polifarmasi}

Menurut WHO, polifarmasi didefinisikan sebagai penggunaan obatyang banyak (umumnya lebih dari lima obat) di saat yang bersamaan oleh seorang individu. Pemberian obat ini bersifat lebih dari kebutuhan rasionalnya terkait dengan 
diagnosis yang diberikan oleh dokter. Dalam konteks ini, terdapat obat-obatan yang dapat dikurangi tanpa memengaruhi efek terapeutik yang diharapkan. Obat-obatan tersebut juga bila ditinjau dari segi biaya masih dapat disesuaikan alternatif pilihan dengan biaya yang lebih murah. Selain itu, risiko efek samping dan interaksi antar obat menjadi perhatian khusus mengingat dapat berdampak fatal. ${ }^{2}$

Terdapat beberapa penyebab timbulnya polifarmasi, antara lain tidak jelasnya tujuan/ target pengobatan, kurangnya pengetahuan mengenai interaksi obat, kecenderungan dokter untuk melakukan "playingsafe", bujukan promosi dari pabrik obat, dan pengobatan dilakukan untuk tiap gejala (terapi simptomatis). ${ }^{1}$

Fenomena polifarmasi utamanya ditemukan pada pasien lanjut usia (geriatri) di mana pasien golongan tersebut cenderung memiliki multiple organ diseases. Pasien geriatri umumnya menjalani pengobatan multidisiplin dan mendapat berbagai obat dari masingmasing disiplin. Bentuk adaptasi atau toleransi tubuh terhadap interaksi obat/efek samping pada pasien geriatri lebih rendah dibandingkan kelompok usia produktif. Oleh karena itu, peresepan rasional menjadi hal utama yang harus diperhatikan dalam pemberian regimen pada pasien geriatri. ${ }^{4}$

\section{Peresepan Rasional}

Dalam melakukan peresepan obat yang rasional, seorang dokter perlu mempertimbangkan risk, benefit, dan cost dari terapi medikamentosa penyakit, komponen usia, keadaan umum, efek terapeutik yang optimal, efek samping yang minimal, kesesuaian bentuk sediaan, keamanan interaksi antar obat, dan keterjangkauan harga. ${ }^{4}$ UU No. 29 Tahun 2004 tentang Praktik Kedokteran Pasal 51 ayat 1 yang menyatakan bahwa dokter atau dokter gigi dalam melaksanakan praktik kedokteran mempunyai kewajiban untuk memberikan pelayanan medis sesuai dengan standar profesi dan standar prosedur operasional serta kebutuhan medis pasien. ${ }^{5}$ Dalam hal ini jelas bahwa pemberian obat-obatan berlebihan yang tidak sesuai dengan kebutuhan pasien atau polifarmasi merupakan praktik medis yang potensial membahayakan pasien.

Dalam konsep peresepan rasional, selain kompetensi dokter, realisasi asas autonomi pasien juga dapat berkontribusi positif. Dalam UU No. 29 Tahun 2004 tentang Praktik Kedokteran Pasal 52 disebutkan bahwa dalam menerima pelayanan praktik kedokteran, pasien berhak untuk mendapatkan penjelasan secara lengkap tentang tindakan medis, termasuk terapi medikamentosa yang akan diberikan. ${ }^{5}$

\section{Kontroversi Puyer}

Masalah kontroversi puyer pernah mencuat di tahun 2009, setelah adanya liputan dari salah satu stasiun TV. Selain kontroversi higienitas alat yang digunakan, polifarmasi dan risiko interaksi antar obat dalam puyer turut menjadi sorotan. ${ }^{6}$ Meskipun terkesan lumrah di Indonesia, pembuatan puyer di negera lain sangat jarang ditemukan. Bukan karena adanya larangan melainkan terdapat beberapa kerugian dari pembuatan puyer terkait dengan stabilitas dan interaksi obat.

Dalam upaya membuat obat dengan stabilitas yang baik, perusahaan farmasi mengeluarkan banyak dana dan melakukan riset hingga didapatkan obat yang stabilitasnya baik. Misalnya, dengan memberikan coating dan menggunakan kemasan blister atau aluminium foil agar terlindung dari perusakan oleh cahaya maupun oksidasi. Proses penggerusan dalam pembuatan puyer dapat mengakibatkan mekanisme pelindung stabilitas obat rusak sehingga stabilitas obat menurun. Yang lebih mengkhawatirkan, masih terdapat dokter yang mencampurkan puyer dalam sediaan sirup (misalnya, OBH) di mana hal tersebut membuat stabilitas obat menurun dan jauh lebih cepat rusak.

Pencampuran beragam jenis obat dalam puyer dapat menyebabkan terjadinya interaksi antar obat dan inkompatibilitas obat. Hal ini dapat menyebabkan efektivitas terapi menurun dan reaksi samping obat. Adanya faktor kesalahan manusia turut menambah kerugian yang dapat terjadi dari pembuatan puyer, seperti salah dalam pengambilan obat, penimbangan obat, dan kurangnya kebersihan. Penggunaan alat penumbuk yang tidak selalu 
dibersihkan sebelum pembuatan puyer tidak hanya meningkatkan risiko kontaminasi mikroba, namun tanpa disadari memungkinkan pencampuran material obat pada komposisi puyer sebelumnya dengan puyer berikutnya.

Rasionalitas peresepan puyer menjadi masalah ketika campuran obat dalam satu puyer terlampau banyak. Praktik polifarmasi pun terkesan tersembunyi dengan adanya persepsi pengobatan dengan satu puyer saja. Untuk mengetahui komposisi puyer yang sedang digunakan bila pasien berobat multicenter, sebagai pertimbangan peresepan rasional, juga menjadi suatu kesulitan tersendiri.

\section{Tinjauan Etika}

Dalam Kode Etik Kedokteran Indonesia (KODEKI) tahun 2012 pasal 7a ditegaskan bahwa seorang dokter dalam setiap praktik mediknya, harus memberikan pelayanan medis yang kompeten dengan kebebasan teknis dan moral sepenuhnya, disertai rasa kasih sayang (compassion) dan penghormatan atas martabat manusia. ${ }^{7}$ Dokter harus memiliki pengetahuan dasar ilmu farmakologi yang cukup mengenai farmakodinamik, farmakokinetik, dan sifat-sifat fisik kimia obat yang akan diresepkan sesuai kompetensi yang dimilikinya.

\section{Perilaku Pasien}

Pola pemikiran masyarakat yang mengharapkan efek secara instan, tidak jarang membuat pasien berpindah dokter (doctor shopping). Dari hasil doctor shopping tersebut kemudian pasien mendapat obat yang terkadang 'berbeda' dibandingkan obat sebelumnya. Perbedaan tersebut umumnya terbatas pada ragam merek, kekuatan, atau sediaannya. Dengan inisiatif sendiri, tidak jarang pasien meminum semua obat dari semua kunjungan dokternya tersebut. Perilaku seperti ini juga dapat berakibat buruk terkait dengan paparan berbagai macam obat dengan dosis dan risiko interaksi antar obat tanpa supervisi dari ahlinya.

Dalam KODEKI Pasal 9 dan 10, disebutkan bahwa seorang dokter wajib bersikap jujur terhadap pasien dan sejawatnya. Seorang dokter wajib menjelaskan secara jujur kepada pasien terkait pilihan pengobatan yang ada serta obat-obatan yang diberikan. ${ }^{7}$ Dengan demikian pasien dapat mengerti obat apa yang diminumnya. Akan tetapi dilema etik terjadi ketika jumlah obat yang diberikan oleh dokter terlampau banyak sehingga edukasi yang disampaikan juga berbenturan dengan keterbatasan daya tangkap pasien. Tidak sedikit pula dokter terlewat untuk menjelaskan karena tergesa-gesa oleh waktu ataupun alasan lainnya.

\section{KESIMPULAN}

Dokter sebagai profesi yang memiliki kompetensi dalam bidang pengobatan mempunyai tanggung jawab untuk berlaku kompeten dan memenuhi hak pasien dengan memberikan penjelasan serta alternatif pengobatan. Dari sudut pandang etika, polifarmasi merupakan tindakan yang potensial mengancam keselamatan pasien.

Setiap dokter dan calon dokter hendaknya memahami dengan menyeluruh teknik peresepan rasional untuk menghindari praktik polifarmasi yang dapat membahayakan pasien. Perlu dipertimbangkan agar Majelis Kehormatan Etik Kedokteran (MKEK) dapat berperan sebagai mediator pembinaan profesi agar tidak terjadi pelanggaran etik terkait dengan praktik polifarmasi di layanan kedokteran Indonesia. Dalam hal ini peran aktif MKEK baik pusat, wilayah, maupun cabang sangat diharapkan, misalnya dalam setiap pertemuan rutin ataupun setiap kesempatan.

\section{KONFLIK KEPENTINGAN}

Penulis tidak memiliki konflik kepentingan dalam penulisan artikel ini.

\section{REFERENSI}

1. Jokanovic N, Tan EC, Dooley MJ, Kirkpatrick CM, Bell JS. Prevalence and factors associated with polypharmacy in long-term care facilities: a systematic review. J Am Med Dir Assoc. 2015;16(6):535.e1-12.

2. WHO. Medication safety in polypharmacy. Geneva: World Health Organization;2019. 
3. Rahmawaty Y, Sunarti S. Permasalahan pemberian obat pada pasien geriatri di ruang perawatan RSUD saiful anwar malang. Jurnal Kedokteran Brawijaya. 2014;28(2):141-5.

4. Gurwitz J, Kapoor A, Rochon P. Polypharmacy, the good prescribing continuum, and the ethics of deprescribing. public policy \& aging report. 2018;28(4):108112.

5. Undang-undang RI Nomor 29 Tahun 2004 Tentang Praktik Kedokteran. Jakarta:2004.

6. Kontroversi puyer dan polifarmasi[Internet]. 2009 Mar [disitasi pada 2020 Jan] dapat diakses pada: www.kompas.com.

7. Kode etik kedokteran Indonesia tahun 2012. Jakarta: 2012. 